\title{
Nanoporous Polyether Sulfone Membrane, Preparation and Characterization: Effect of Porosity and Mean Pore Size on Performance
}

\author{
Sara Salehi Shahrabi ${ }^{1}$, Hamid Reza Mortaheb ${ }^{1, *}$, Jalal Barzin $^{2}$ and \\ Mohammad Reza Ehsani ${ }^{3}$ \\ ${ }^{1}$ Chemistry and Chemical Engineering Research Center of Iran, Tehran, P.O. Box: 14335-186, Iran \\ ${ }^{2}$ Iran polymer and petrochemical institute, Tehran, P.O. Box: 14965-115, Iran \\ ${ }^{3}$ Chemical Engineering Dep., Isfahan University of Technology, Isfahan 84155, Iran
}

\begin{abstract}
Flat sheet membranes were prepared by phase inversion technique using polyether sulfone (PES) dissolved in dimethylacetamide (DMAc) with and without adding polyvinylpyrrolidone (PVP) or polyethyleneglycol (PEG). The characteristics of the prepared membranes were evaluated using Scanning Electron Microscope (SEM) images, Atomic Force Microscopy (AFM), and Optical Contact Angle (OCA) measurements, and porosity tests. The porosity test and SEM images show that increasing additives to a certain value increases the porosity of the membrane. Also, as the coagulation bath temperature is increased, the porosity of the membrane is increased. The roughness of the membrane is increased by increasing the additive concentration. The analysis of AFM images confirms the nanoporous structure of the prepared membranes, and that the membranes with appropriate pore size distribution can be prepared by the applied method. Permeability tests using single-layer membranes show that the direct relationship between porosity and the flux of pure water or salt solution is dominated by the effect of applied additive while the salt rejection shows an inverse relationship with the mean pore size regardless of the applied additive. The salt permeation flux is a function of total porosity while the salt rejection is a function of surface porosity. Pervaporation tests show that both permeation flux and enrichment factor depend on the total porosity of the support membrane.
\end{abstract}

Keywords: PES membrane, Porosity, Mean pore size, Permeability test, Pervaporation.

\section{INTRODUCTION}

Growing attentions to membrane processes in recent years for different applications such as removal of volatile organic compounds from wastewater [1-3], dehydration of solvents [4,5], and organic-organic separations $[6,7]$ demand exact understanding about the performance of the membranes. The membrane process operates based on different driving forces i.e. the processes such as nanofiltration, ultrafiltration, microfiltration, and reverse osmosis utilize total pressure driving force while the processes such as gas separation and pervaporation operate based on the partial pressure driving force $[8,9]$. Therefore, the membrane properties such as its morphology have distinctive effects on the process operation. These properties are affected in a single-layer membrane by preparation procedure of the membrane [10], choosing the number and types of non-solvents [11], solvents and additives [12], crosslinking agents [13], and polymer inherency [14]. The effects of membrane properties on operational performance have been investigated qualitatively for the filtration process [15, 16]. The ultrafiltration Poly(vinyl chloride) membranes

*Address correspondence to this author at the Chemistry and Chemical Engineering Research Center of Iran, Tehran, P.O. Box: 14335-186, Iran; Tel: +9821 44787 751; Fax: +9821 44787 781; E-mail: mortaheb@ccerci.ac.ir prepared by combination of thermally induced phase separation and non-solvent-induced phase separation techniques indicated that the changes in the contents of diluents changes the pore size and porosity of the membranes and consequently their rejections and fluxes [17]. However, there are few researches, in which the effects of pore size distribution on the performance of composite membranes are studied.

A membrane for pervaporation process can be made of a thin dense layer supported by a porous sublayer. Theoretically, the active top layer in a composite membrane should provide appropriate selectivity and sufficient permeation flux while the support layer must exhibit outstanding mechanical strength without interfering in the mass transfer. However, several studies have demonstrated that the support layer significantly affects the pervaporation performance [18]. Tan et al. made different polysulfone membranes as support layers by varying polymer concentration in the casting solution and the evaporation time [19]. The results indicated that the support layer with significant resistance can dominate the pervaporative performance of the composite membrane and that the inhomogeneity of the support layer may produce extra mass transfer resistance when the resistance of support layer cannot be neglected [19]. Bode and Hoempler [20] by applying a mass transfer model 
concluded that about $80 \%$ of mass transfer resistance is comprised in the support layer. In a later research, it was found that the permeation rate in the pervaporation can be enhanced significantly when the intrusion of cast top layer in the pores of support layer is prohibited $[21,22]$. Trifunovic et al. studied the effect of polyetherimide and polyacrylonitrile membranes as the supports of composite membranes on the mass transfer rate in hydrophobic pervaporation for removal of alcohols and esters [23]. It was observed that the dependency of pervaporative separation is not only related to the geometric characteristics of the support but also to its nature [23]. It has been concluded that permeate-side pressure losses in the support pores can be important [24]. The performance of a pervaporation membrane having a bigger pore size and porosity was found to be superior to that of a membrane with smaller ones. In addition, it was found that the controlling step of mass transfer is changed from concentration polarization to membrane resistance by increasing the feed flowrate [25]. The water selective pervaporative performance of an ultrathin polysiloxaneimide (PSI) top layer on polyetherimide (PEI) support in a composite hollow fiber was attributed to the influence of hydrophilic PEI layer in a research by Zhu et al. [26].

None of the above researches have studied the effect of support layer porosity and pore size distribution on the performance of the composite membranes.

Polyethersulfone (PES) is considered as a suitable material for support membrane due to its favorable mechanical strength, resistance to acids and alkalis, and high thermal and chemical resistances. In the present research, membranes are prepared by blends of PES as the membrane matrix, and polyvinyl pyrrolidone (PVP) or polyethylene glycol (PEG) as the hydrophilic additives. These membranes are characterized by structural analyses, and their porosity and pore size distributions are determined. The membranes are then applied in permeability and pervaporation tests, and the effects of those parameters on the operation performance are investigated $[27,28]$.

\section{EXPERIMENTAL}

\section{Materials}

Polyethersulfone (Ultrason $\mathrm{E} 6020, \mathrm{Mw}=58,000$ ) was supplied from BASF, Germany. Dimethyl acetamide (DMAc) and tetraethyl orthosilicate (TEOS) were obtained from Merck (Germany). Poly dimethyl siloxane, (PDMS, viscosity $=5000 \mathrm{MPa} . \mathrm{s}$ and average molecular weight $=40,000)$, dibutyltin dilaurate $(D B T L)$, PEG $(M w=400)$, and poly vinyl pyrrolidone (PVP, K90, $M w=360,000)$ were purchased from Sigma-Aldrich, USA.

\section{Membrane Preparation}

PES flakes were dried in an oven to remove their adsorbed water in advance. Homogeneous casting solutions were made by dissolving PES, and PVP or $P E G$ in DMAc. The compositions of casting solutions were adapted by changing the percentage of PES and the additive. Three concentrations of PES $(15,18$, and $22 \mathrm{wt} \%)$, three concentrations of PVP $(3,5$, and 10 wt.\%), and two concentrations of PEG (5 and $10 \mathrm{wt} \%$ ) were tested for preparation of the membranes. Asymmetric flat membranes were prepared using phase inversion technique. The solutions of mixed polymers were well homogenized by a magnet stirrer and were cast smoothly on a level glass plate by a casting knife at room temperature. The film thickness was set to $200 \mu \mathrm{m}$ for all the membranes. The layered polymers on the glass plates were immediately immersed in the coagulation bath for all the trials. The membranes were then stored in distilled water for $48 \mathrm{~h}$ to allow the water-soluble components in the membranes to be leached out. As the final stage, the membranes were washed again with distilled water and were dried by filter papers to be stored for at least $48 \mathrm{~h}$ at room temperature.

For preparation of the active layer, PDMS was dissolved in $\mathrm{n}$-heptane to form a $50 \mathrm{wt} \%$ solution. The crosslinking agent, TEOS, and the catalyst, DBTL, with respectively $0.1 / 0.02$ weight ratios of the polymer were then dissolved in the solution. The solution was stirred vigorously for $2 \mathrm{~h}$ at room temperature. Prior to the coating step, the PES support was pre-wetted by glycerol in a pan to reduce mass transfer resistance due to penetration of PDMS solution into the porous substrate. Excess glycerol on the PES support surface was then wiped off with a filter paper. The support layer was put into a glass mold, and the PDMS solution was spread out uniformly on its surface. The active layers were allowed to be partially crosslinked at room temperature in $24 \mathrm{~h}$. The membrane was put into an oven set to $70{ }^{\circ} \mathrm{C}$ afterward for $4 \mathrm{~h}$ to complete the crosslinking.

\section{Characterization of PES Single Layer Membranes}

SEM was used to observe the structure of the support layer (VEGA 3 SBHIITescan Brno, Check). 
PES membranes were snapped in liquid nitrogen to give a clean break. The samples were then placed on a sample stand and coated with gold by sputtering.

Atomic Force Microscopy (Dual scope C-26 DME, Denmark) was applied to measure the pore sizes in the membrane. The distribution of pores in the membrane was then determined by using Sigmaplot mathematical software.

The contact angle and hence wettability behavior of the prepared membranes were measured by an Optical Contact Angle measuring instrument (OCA-20, Dataphysics, Germany).

A viscometer (AMVn1569 Anton Paar Austria) was used to measure the solution viscosity.

The prepared PES membranes were immersed in solution of $30 \mathrm{wt} \%$ glycerol for 5 days at room temperature. The weight of membranes was then recorded and porosity was calculated using the following equation [29]:

$P=\frac{\left(Q_{0}-Q_{1}\right)}{A \cdot h \cdot \rho} \times 100 \quad(\%)$

Here $P$ is the membrane porosity, $Q_{0}$ and $Q_{1}$ are the weights of wet and dried membranes $(\mathrm{g})$, respectively, $A$ is the membrane surface area $\left(\mathrm{cm}^{2}\right), h$ is the membrane thickness $(\mathrm{cm})$, and $\rho$ is the density of liquid $\left(\mathrm{g} / \mathrm{cm}^{3}\right)$. In order to minimize the experimental error, the membrane porosity of each sample was measured three times.

\section{Water Permeability and Membrane Performance}

\section{Water Permeability Test}

Water permeability tests through the prepared support membranes were performed by a cross-flow setup under steady state conditions. The setup consists of a reservoir, a pump, valves, pressure regulators, and a membrane cell as illustrated in Figure 1. The prepared membranes were cut into the desired size for fixing on the setup. The membrane cell was initially pressurized with distilled water to a transmembrane pressure of $200 \mathrm{kPa}$. Water permeability is calculated as follows [30]:

$$
L_{p}=\frac{V}{A \cdot \Delta t \cdot \Delta P} \quad\left(\mathrm{~L} / \mathrm{h} \cdot \mathrm{m}^{2} \cdot \mathrm{bar}\right)
$$

where $L_{p}$ is the pure water permeability, $V$ is the volume of water permeated through the membrane $(L)$, $A$ is the membrane area $\left(\mathrm{m}^{2}\right), \Delta t$ is the operation time (h), and $\Delta P$ is the transmembrane pressure (bar).

\section{Salt Rejection Test}

The filtration performances of the membranes were evaluated using the setup. The solution of $\mathrm{NaCl}$ in deionized water with a concentration of $2 \mathrm{~g} / \mathrm{lit}$ was used for all the experiments. All experiments were performed under pressure of $200 \mathrm{kPa}$.

The permeation flux is calculated using Eq. (2), and the salt rejection is calculated as follows:

$$
\text { Rejection }=\frac{C_{\mathrm{f}}-C_{\mathrm{P}}}{C_{\mathrm{f}}} \times 100
$$

where $C_{f}$ and $C_{p}$ are the salt concentrations in the feed and permeate streams, respectively, measured by a conductivity meter.

\section{Pervaporation}

Pervaporation experiments were carried out using a laboratory setup. The details of the setup were previously reported [31]. The flat composite membrane was fixed on the cylindrical pervaporation cell. The effective area of the membrane was $10 \mathrm{~cm}^{2}$ and the

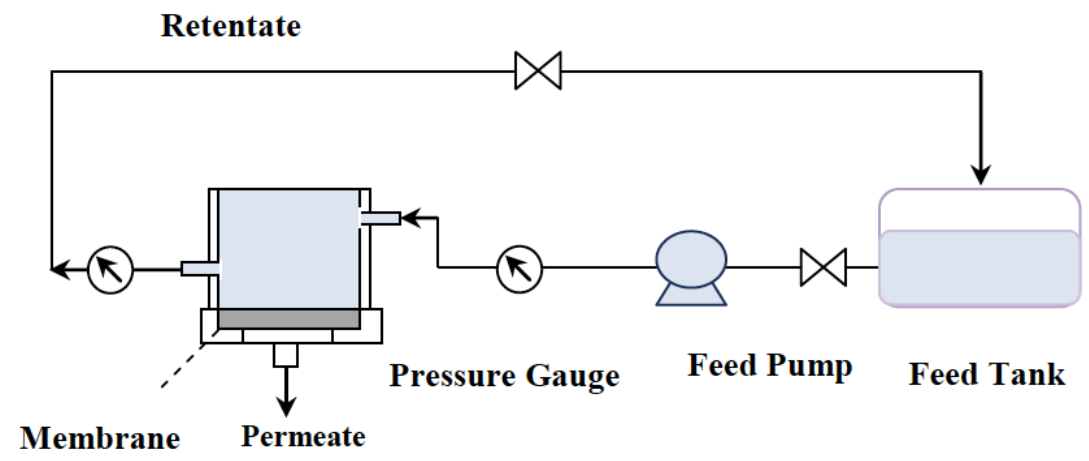

Figure 1: Schematic diagram of filteration set up. 
permeate pressure was 1 mbar. The permeate was collected in a cold trap chilled by liquid nitrogen.

Pervaporative performance of the composite membrane can be assessed in terms of permeate flux $(J)$ and enrichment factor $(\beta)$ using the following equations:

$J=\frac{M}{A \cdot t} \quad\left(\mathrm{~g} / \mathrm{m}^{2} \cdot \mathrm{h}\right)$

$\beta=\frac{C_{\mathrm{A}}^{\prime}}{C_{\mathrm{A}}}(-)$

where $M(\mathrm{~g})$ is the total mass of permeate during the experimental time interval of $t(\mathrm{~h})$ at steady state, $A$ $\left(\mathrm{m}^{2}\right)$ is the effective membrane area, and $C_{A}^{\prime}$ and $C_{A}$ (ppm) are the toluene concentrations in the permeate and retentate, respectively. The toluene concentration in the permeate is calculated by:

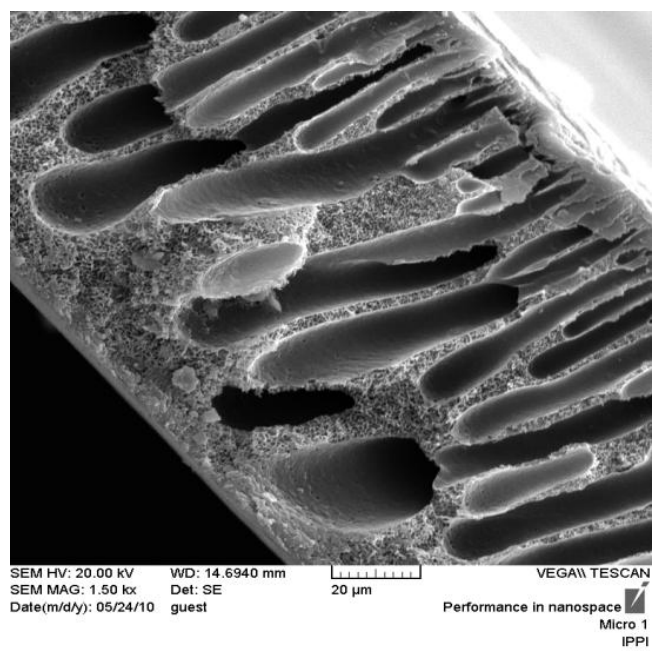

(a)
$C_{A}=\frac{m_{\mathrm{A}}}{V_{\mathrm{P}}} \quad(\mathrm{mg} / \mathrm{L})$

in which, $m_{\mathrm{A}}(\mathrm{mg})$ is the mass of permeated toluene calculated from retentate volume and its composition by a mass balance, and $V_{P}(L)$ is the total permeate volume.

Aqueous solutions of toluene with a concentration of $150 \mathrm{ppm}$ were used as the feed in the experiments. Each experiment was repeated three times.

\section{RESULTS AND DISCUSSION}

\section{Effect of Polymer Concentration on Membrane Morphology}

Three different membranes with PES concentrations in the range of $15-22 \mathrm{wt} \%(15,18$ and 22 wt\%) were made and the porosities of the

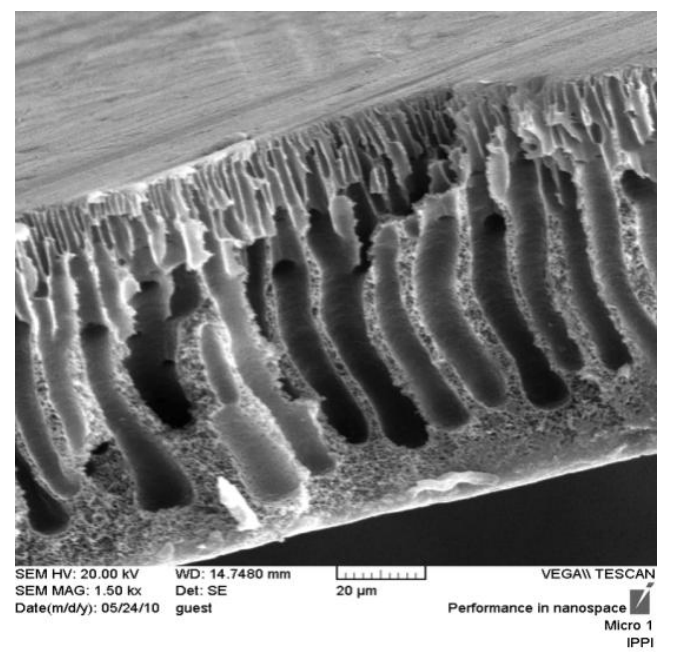

(b)

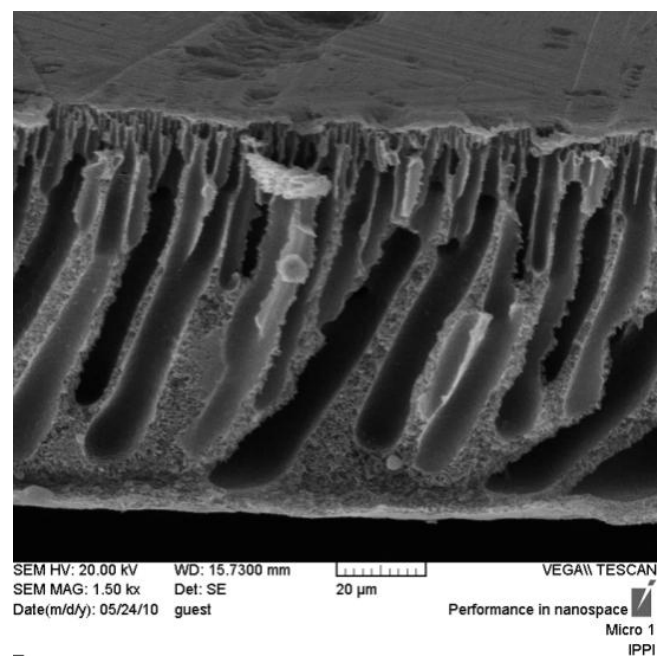

(c)

Figure 2: SEM images of (a) 15 wt $\%$ PES, (b) 18 wt $\%$ PES, (c) 22 wt $\%$ PES, without additive, $T_{\text {bath }}=40^{\circ} \mathrm{C}$. 
membranes were measured. As shown in Figure 2a, a wide finger-like structure is observed in the membrane with $15 \mathrm{wt} \%$ PES. The structure is changed to thin finger-like pores with some sponge areas between them by increasing in polymer concentration to $18 \mathrm{wt} \%$. More increasing in polymer concentration will increase the sponge areas while the number of finger pores is decreased.

The porosities of the membranes for different PES concentrations are shown in Figure 3. Again, it is observed that the porosity of membrane is decreased significantly by increasing polymer concentration due to decrease of free areas between the polymer chains. Meanwhile, all fabricated membranes had enough mechanical strength so that the membrane with the minimum PES concentration (15 wt\%) can be used for further experiments. It is noticeable that the current research is focused mainly on the membranes with PES concentration within the range of $15-22$ wt $\%$ since the mechanical strength of the membrane is decreased significantly when the polymer concentration falls below $12 \mathrm{wt} \%$ [32], in which the formation of macrovoids renders the strength of the membrane. On the other hand, in concentrations higher than $22 \mathrm{wt} \%$ PES, the prepared membranes have irregular structures [33-35].

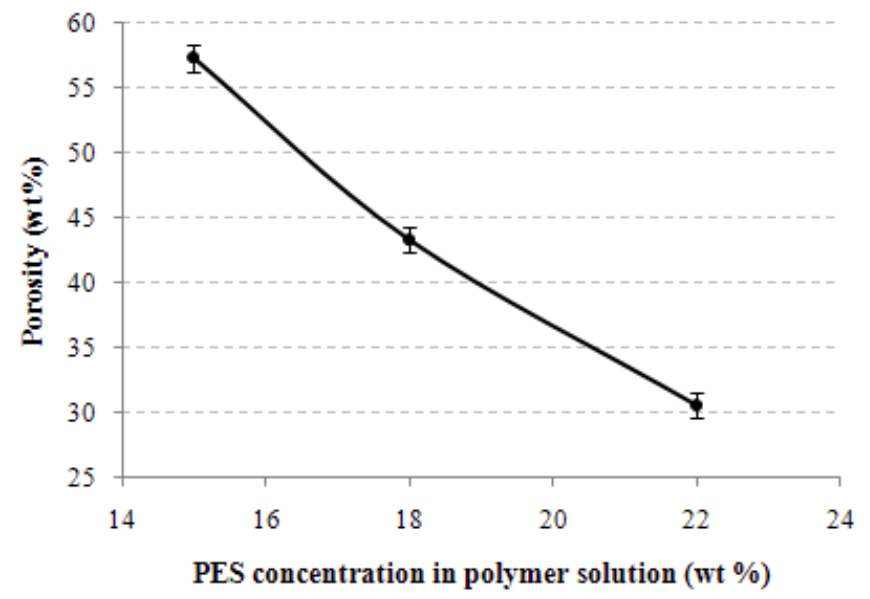

Figure 3: Effect of PES concentration in polymer solution on membrane porosity.

\section{Effect of PEG and PVP Concentrations on Morphology of Membrane}

Hydrophilic additives as materials with non-solvent properties would increase thermodynamic instability of the immersed film. These properties are caused by the strong and weak miscibilities of the additive with the solvent and the polymer, respectively. When a hydrophilic additive is added to the polymer solution, the exchange rate of solvent-water in the coagulation bath increases at the phase inversion step. Subsequently, more voids are created in the structure of the membrane, which exhibit a large channel-like or finger-like form [36-38]. Therefore, a thick macrovoid membrane is formed as a result of instantaneous demixing due to thermodynamic instability. On the other hand, increasing additives will increase viscosity of the solution. Since increasing viscosity is an obstacle for instantaneous de-mixing of the solvent and nonsolvent, additives in the polymer may have a bilateral effect on the morphology and porosity of the membrane i.e. membranes with either high or low porosities can be formed by adding additives to the polymer $[39,40]$.

In the present research, PEG (400) and PVP $(360,000)$ were added to a solution with $15 \mathrm{wt} \%$ PES for investigating the influence of the additive concentration on porosity. The measured viscosities of primary solutions are shown in Table 1.

Table 1: Viscosities of Polymer Solution without and with $\mathrm{PEG}_{400}$ or $\mathrm{PVP}_{360000}$ as Additive

\begin{tabular}{|c|c|c|c|}
\hline $\begin{array}{c}\text { PES conc. } \\
\text { (wt\%) }\end{array}$ & $\begin{array}{c}\text { PEG conc. } \\
\text { (wt\%) }\end{array}$ & $\begin{array}{c}\text { PVP conc. } \\
\text { (wt\%) }\end{array}$ & $\begin{array}{c}\text { Viscosity } \\
\text { (cP) }\end{array}$ \\
\hline \hline 22 & 0 & 0 & 2152.3 \\
\hline 18 & 0 & 0 & 682.9 \\
\hline 15 & 0 & 0 & 276.3 \\
\hline 15 & 5 & 0 & 354.3 \\
\hline 15 & 10 & 0 & 429.3 \\
\hline 15 & 0 & 3 & 1099.3 \\
\hline
\end{tabular}

The morphologies of the membranes prepared from PES/PEG (or PVP)/DMAc systems are shown in Figure 4. It is noticeable in this figure that the macrovoids are covered by a thin inherent dense top layer. The fingerlike structure with some sponge areas for the membrane without additive (Figure 2a) changes to a channel-like macrovoid structure by adding $5 \mathrm{wt} \%$ PEG (Figure 4a). When PEG concentration is increased to $10 \mathrm{wt} \%$, the pore size is decreased (Figure $\mathbf{4 b}$ ) and a thin channel-like structure with closed ends are formed possibly due to dominant kinetic effect and inhibition against instantaneous de-mixing. The porosity of the membrane is plotted against PEG concentration in Figure 5a.

As seen in Figures $\mathbf{2 a}$ and $\mathbf{4 c}$, by increasing PVP concentration from 0 to $3 \mathrm{wt} \%$, the finger-like structure of the membrane changes and regular channel-like macrovoids with closed ends are formed. As the PVP concentration is increased to 5 and 8 wt\% (Figures $\mathbf{4 d}$, e), the structure of the pores changes from a long 


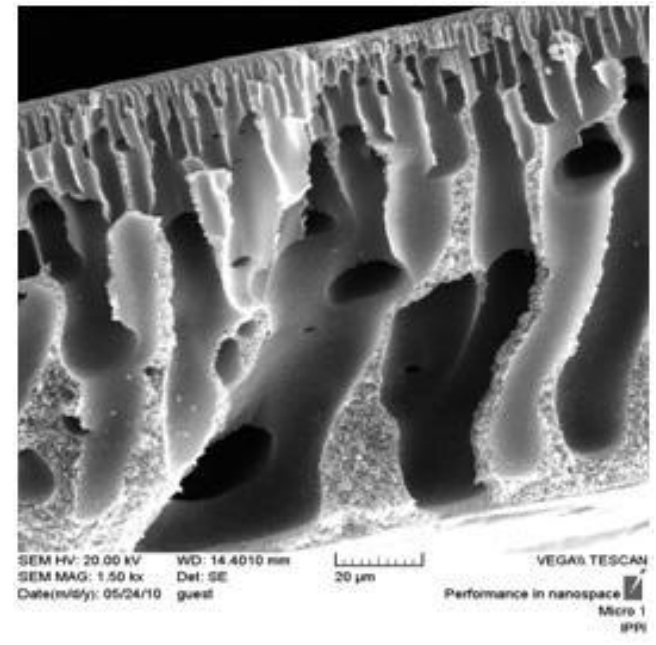

(a)

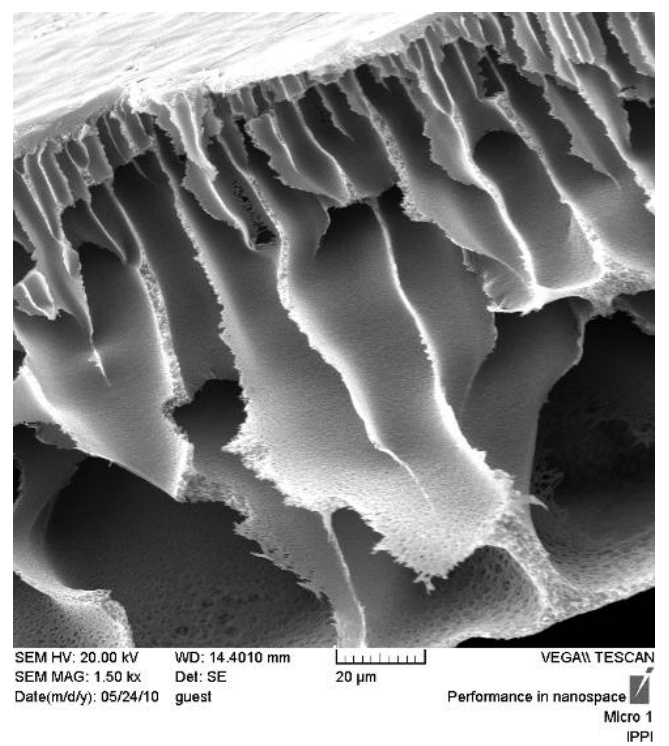

(c)

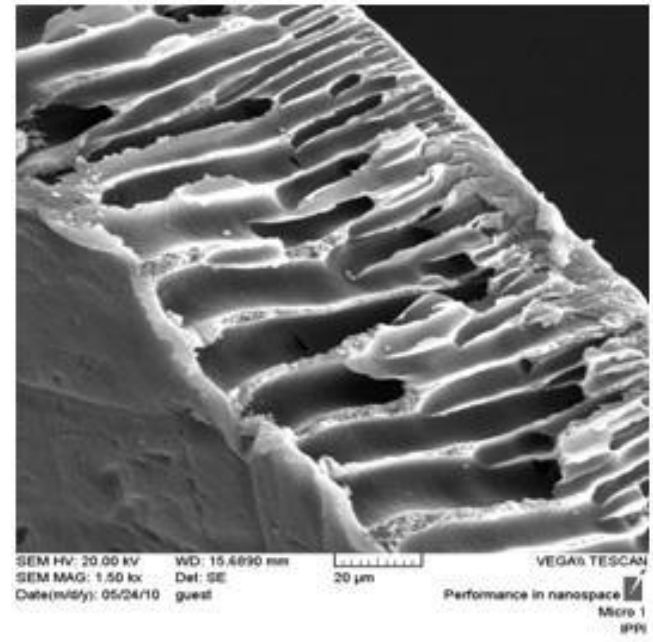

(b)

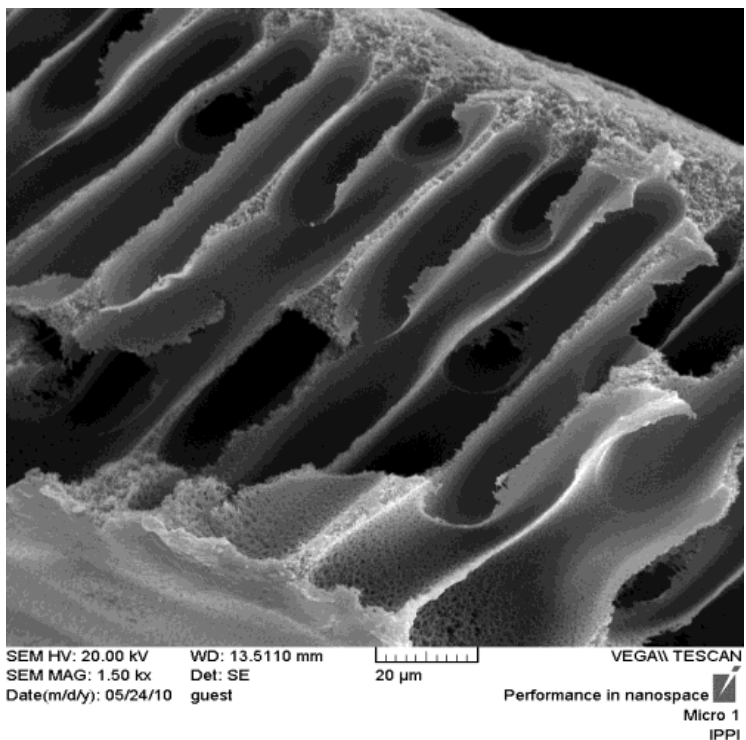

(d)

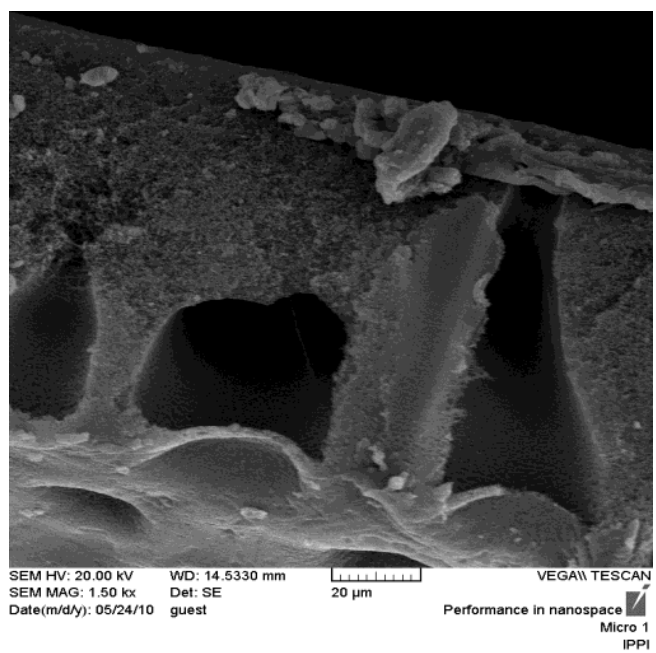

(e)

Figure 4: SEM images of 15 wt $\%$ PES membrane with (a) 5 wt\% PEG, (b) 10 wt\% PEG, (c) 3 wt\% PVP, (d) 5 wt\% PVP, and (e) $8 \mathrm{wt} \%$ PVP, $T_{\text {bath }}=40^{\circ} \mathrm{C}$. 


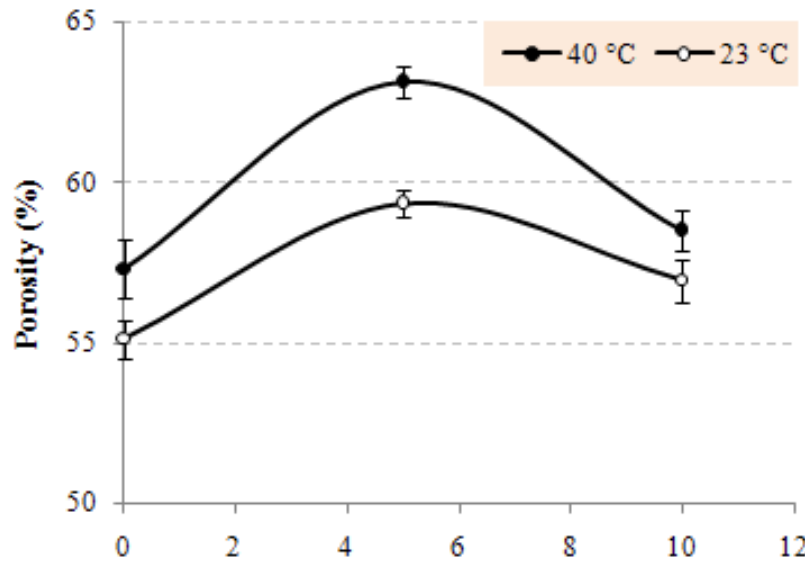

PEG concentration in polymer solution (wt \%)

(a)

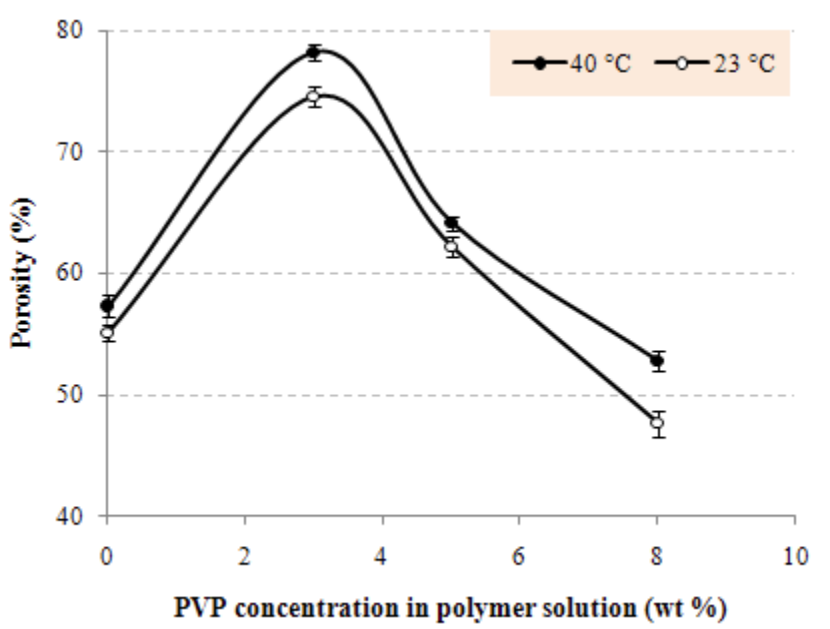

(b)

Figure 5: Effect of (a) PEG and (b) PVP concentrations in polymer solution on membrane porosity.

finger/channel-like to a sponge-like structure with tearlike ends. In addition, similar trend of change in the porosity as that in the membranes with PEG can be observed here that is increasing in porosity by adding the PVP concentration up to a certain level and then decreasing by further adding the additive (Figure $\mathbf{5 b}$ ). The maximum porosity of the membrane is achieved with PVP concentration of about $3 \mathrm{wt} \%$. It is also observed by comparing Figures $\mathbf{5 a}$ and $\mathbf{5 b}$ that the maximum porosity of the membrane obtained by adding PVP is higher than that obtained by adding PEG.

\section{Effect of Coagulation Bath Temperature on Morphology of Membrane}

Increasing the coagulation bath temperature augments the thermodynamic instability, which is believed to be due to delaying in de-mixing [39-41]. During the coagulation process, the molecules in the cast film are exchanged with the non-solvent molecules in the coagulation bath. At constant temperature of the cast film, increase in the temperature of the coagulation bath increases the exchange rate [37]. The following SEM images verify this statement. Increasing in the bath temperature changes the membranes structure from the thin closed-end channels (Figure 6) to a structure of wide channels with the open ends (Figure 4c). Also, the formation of macrovoid channels is approached more to the top surface of the membrane as the bath temperature is increased.

The effects of coagulation bath temperature on porosity are also shown in Figures $\mathbf{5 a}$ and $\mathbf{5 b}$, in which higher porosities are obtained by increasing the bath temperature.

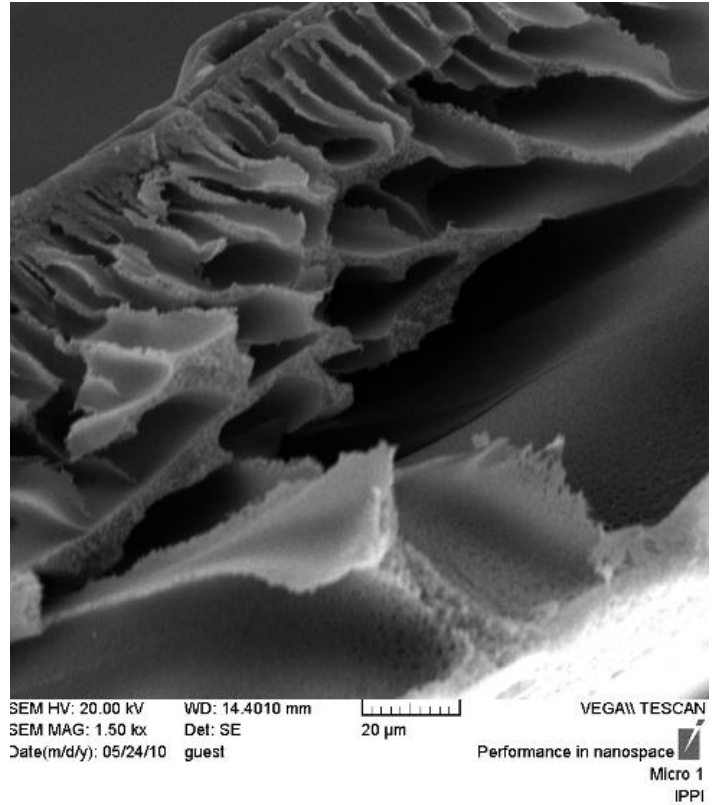

Figure 6: SEM images of $15 w t \%$ PES membrane with $3 w t \%$ $\mathrm{PVP}$, coagulation bath at room temperature.

\section{Effect of Additive Concentration on Surface Roughness of Prepared Membranes}

Three-dimensional AFM images of the prepared membranes by PES, PES+PEG, and PES+PVP with different additive concentrations are shown in Figure 7. Comparing the images reveals that the roughness of the membrane is generally decreased by using an additive. Figures $\mathbf{7 b}$ and $\mathbf{c}$ show that as the PEG concentration is increased from 5 to $10 \%$, the number of holes, shown in dark color, is increased possibly because of leaching out of PEG from the membrane matrix during the coagulation step. Even a more decrease in the surface roughness is observed by applying PVP as the additive. However, the number of 


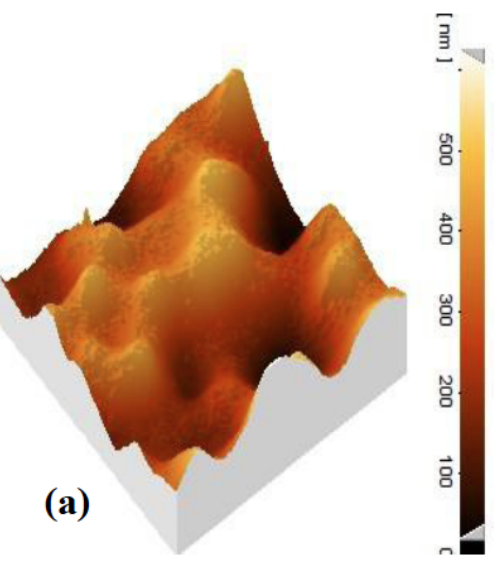

(b)

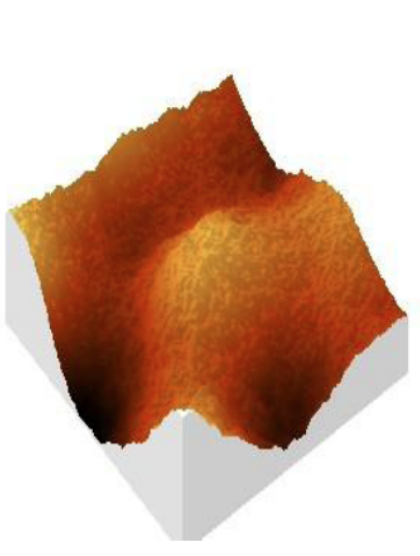

(d)

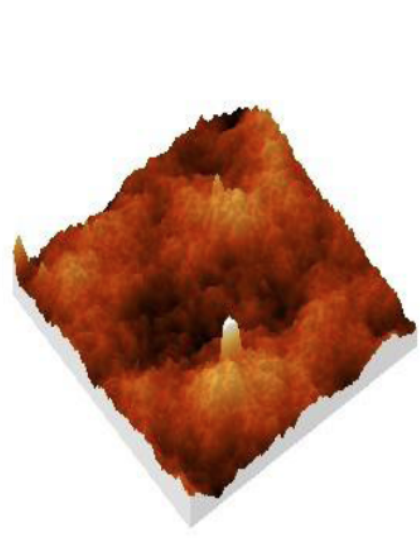

(e)

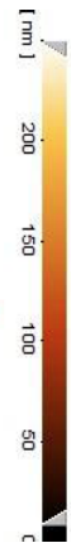

亲.



亲

(c)
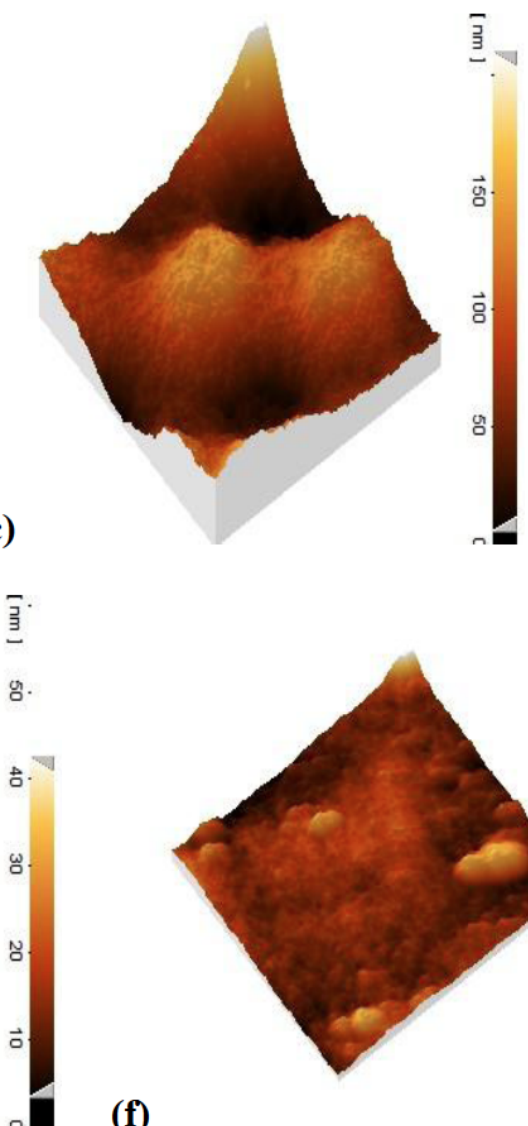

(f)
梠.

g.

亲.
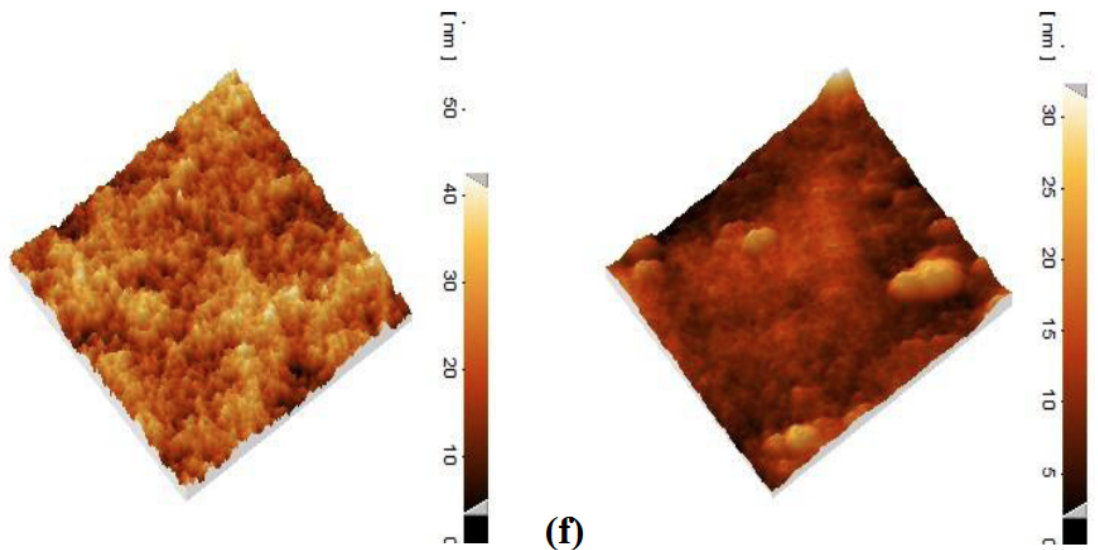

Figure 7: AFM images of membranes having 15 wt $\%$ PES with (a) $0 \%$ additive, (b) 5 wt $\%$ PEG, (c) 10 wt $\%$ PEG, (d) 3 wt $\%$ PVP, (e) 5 wt $\%$ PVP, and (f) 8 wt $\%$ PVP.

holes is decreased as the PVP weight percent is increased from 3\% (Figure 7d) to 5 and $8 \%$ (Figures 7 e and $\mathbf{7 f}$, respectively). This may show that less molecules of PVP leave the polymer matrix during the coagulation step because of their large molecular size.

Arithmetic mean deviation $\left(S_{a}\right)$ as an index of roughness, for the prepared membranes is shown in Figure 8. The figure shows that as the additives concentration is increased, the surface roughness of the membrane is decreased. Figure 8 also shows the contact angles of the membranes. As seen, the contact angle is decreased by decreasing the surface roughness. This is in agreement with the results of previous researches, in which it was found that hydrophobic (or hydrophilic) properties are stepped down with decreasing the surface roughness [42].

Figure 9 shows a typical SEM image of fabricated composite membranes. As seen in the figure, the dense PDMS top layer with about $20 \mu \mathrm{m}$ thickness is separated distinctly from the porous support. This 
means that inherent thin layer on the porous support can preserve well the sublayer from intrusion of the PDMS top layer during prewetting step.

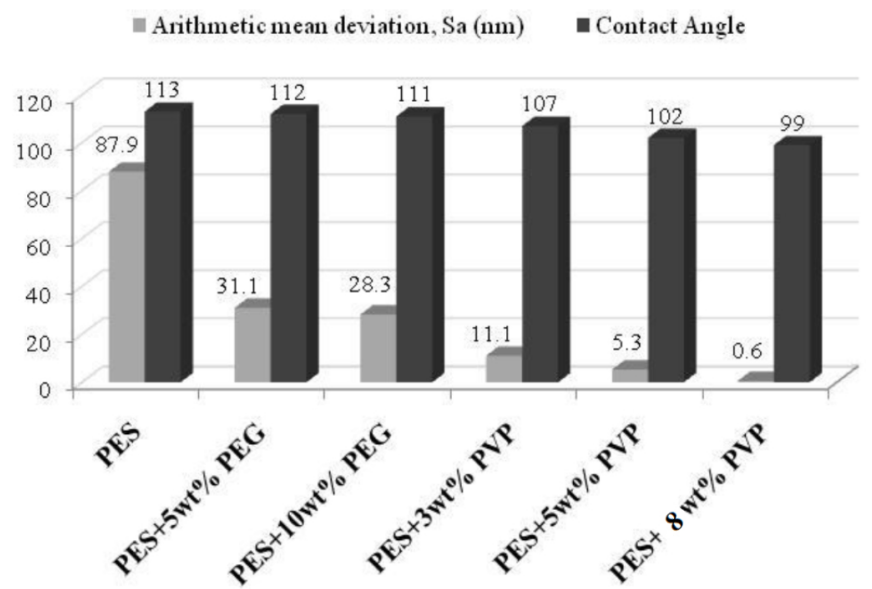

Figure 8: Arithmetic mean deviations and contact angles of membranes.

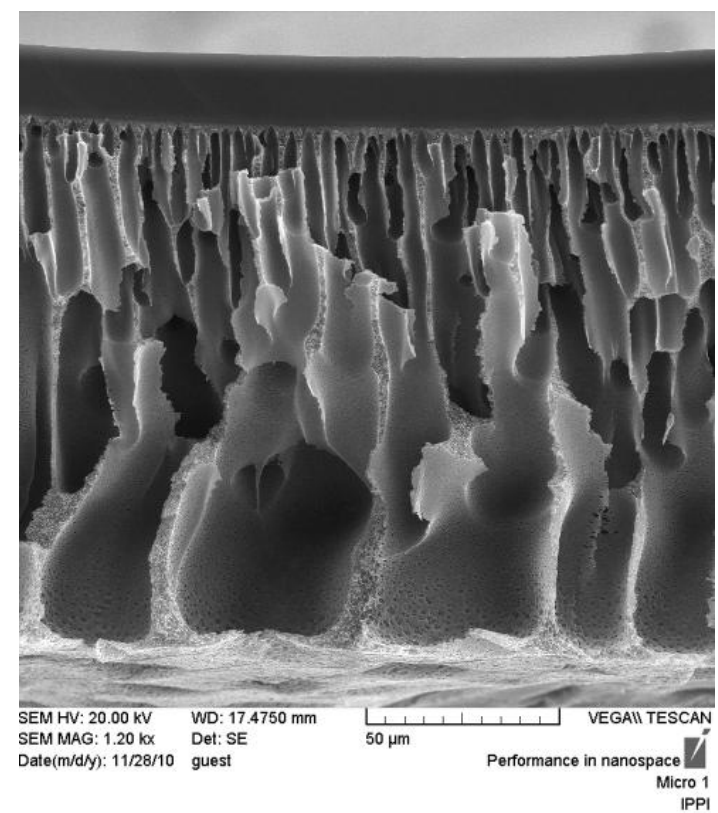

Figure 9: SEM image of PDMS/PES composite membrane; porous support: $15 w t \%$ PES $+3 w t \%$ PVP, $T_{\text {bath }}=40^{\circ} \mathrm{C}$.

\section{Effect of Additive Concentration on Pore Size Distribution of Prepared Membranes}

Pore sizes distribution was obtained by random selecting of linear profiles for 50 segments in different parts of the membrane surface. A pore size was then determined by peaking up a pore from the expanded curve of each profile. The pore sizes were plotted on the normal logarithmic distribution graph (Figure 10) by SigmaPlot mathematical software where the vertical axis indicates the frequency percentage of the pore size. The mean pore sizes of the membranes equivalent to the pore sizes in $50 \%$ frequency, and the standard deviations based on the following equation are listed in Table 2.

$S . D=\frac{\text { Pore size in } 50 \% \text { Frequency }}{\text { Pore size in } 84.13 \% \text { Frequency }}$

The results show that increasing in additive concentration decreases the mean pore size. The probability density function curves of the prepared membrane are shown in Figure 11. The figure shows that as the additive concentration in the membrane increases, the curve demonstrates a narrower distribution with a peak at a smaller pore size. The narrowest curve is corresponded to the PES membrane with 10\% PVP while the widest distribution is corresponded to the PES membrane without additive. According to the results, all the membranes can be categorized in the range of nanoporous membranes.

\section{Effect of Membrane Porosity on Pure Water Permeability}

In order to verify the effect of membrane porosity on permeation flux, a series of filtration tests were performed using the explained setup. The results in Table 3 show that for the membranes containing PEG, permeation flux follows the changes in porosity of the membranes i.e. increases with increasing porosity and vice versa. However, for the membranes containing PVP, a different trend is observed that is while the porosity reaches to a maximum value by increasing PVP and then decreases, a steadily increase in permeation flux is observed with increasing PVP concentration. The measured values of surface contact angle (Figure 8) show that by increasing PVP concentration in the polymer solution, the membrane becomes more hydrophile possibly because of more residual content of PVP on the membrane's surface as well as inside the membrane. However, the contact angles of the membranes containing PEG in their polymeric solution do not change significantly since majority of $P E G$ is leached out during immersing membrane in the water bath. Therefore, it may be concluded that the permeation flux in the membranes with higher concentration of PVP may be increased due to an enhancing adsorption effect of the PVP lumps, which is trapped in the membrane structure. These adsorption sites may produce additional paths for permeate through the membrane and then increase the permeation flux. 


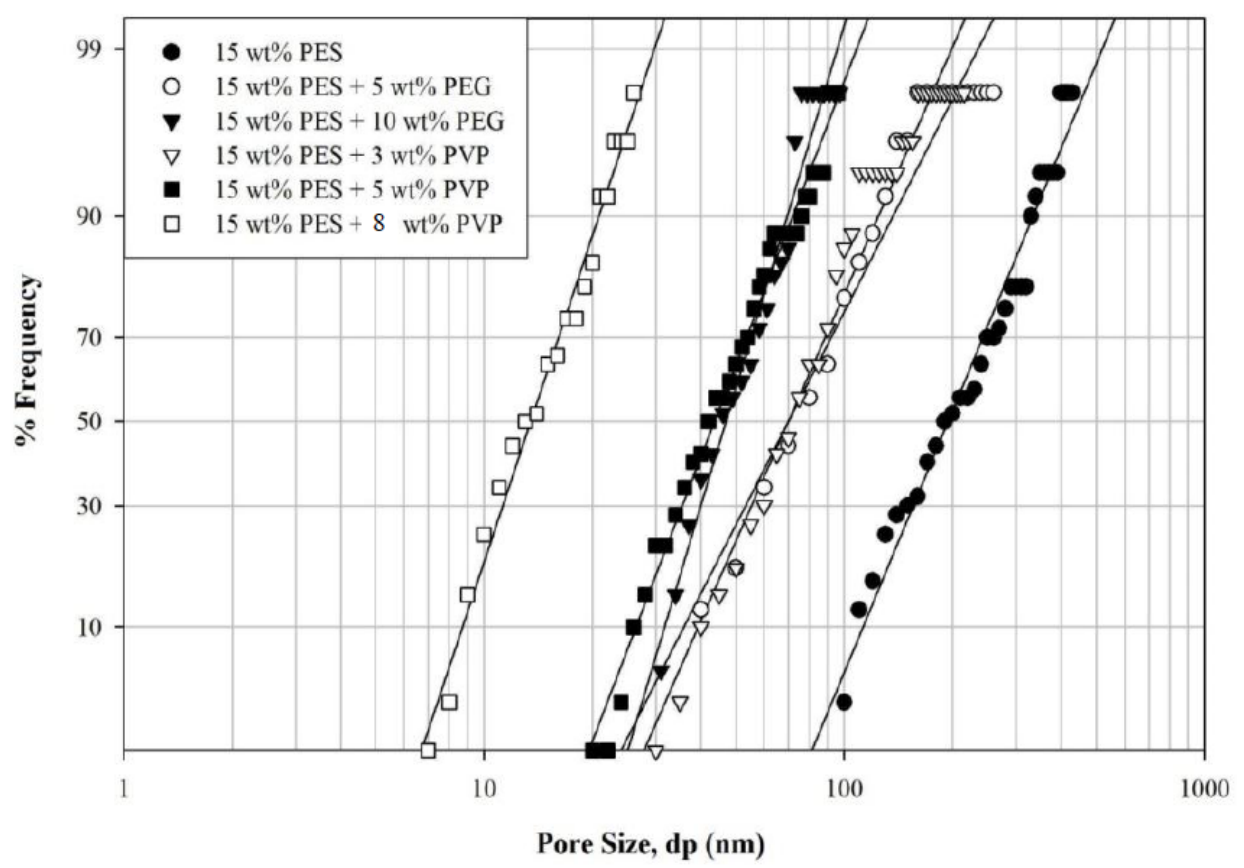

Figure 10: Normal logarithmic distributions of pore sizes for different membranes.

Table 2: Mean Pore Sizes and Standard Deviations of Prepared Membranes

\begin{tabular}{|c|c|c|}
\hline Polymer contents & Mean pore size (nm) & Standard derivation \\
\hline \hline $15 w t \%$ PES & 190.54 & 1.57 \\
\hline $15 w t \%$ PES +5wt\% PEG & 69.00 & 1.69 \\
\hline $15 w t \%$ PES +10wt\% PEG & 47.30 & 1.64 \\
\hline $15 w t \%$ PES +3wt\% PVP & 70.00 & 1.48 \\
\hline $15 w t \%$ PES +5wt\% PVP & 43.65 & 1.40 \\
\hline
\end{tabular}

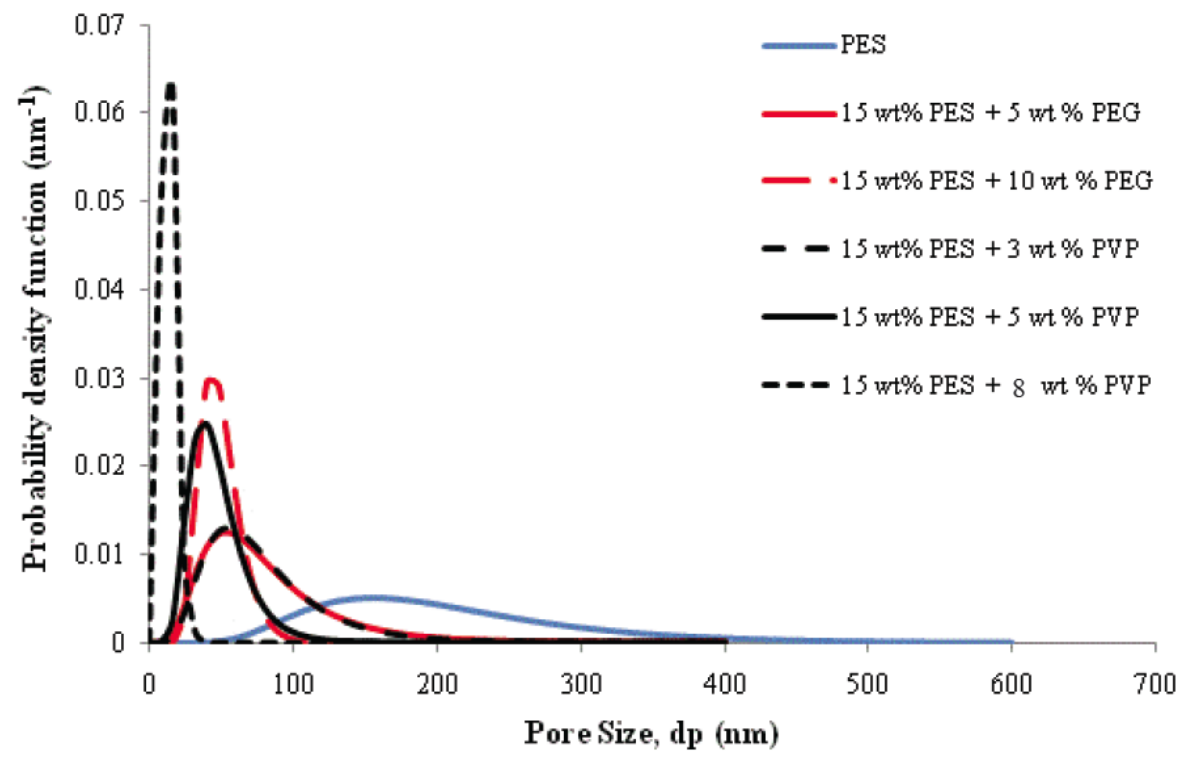

Figure 11: Probability density functions of membranes. 
Table 3: Pure Water Permeabilities of Prepared Membranes, $T_{\text {bath }}=40{ }^{\circ} \mathrm{C}$, PES conc. $=15$ wt $\%$.

\begin{tabular}{|c|c|c|c|}
\hline $\begin{array}{c}\text { PEG conc. } \\
(\mathbf{w t} \%)\end{array}$ & $\begin{array}{c}\text { PVP conc. } \\
\text { (wt\%) }\end{array}$ & $\begin{array}{c}\text { Porosity } \\
\text { (\%) }\end{array}$ & $\begin{array}{c}\text { Water flux } \\
\left(\mathbf{L} / \mathbf{m}^{2} . \mathbf{h} . \mathbf{b a r}\right)\end{array}$ \\
\hline \hline 0 & - & 57.3 & 6.4 \\
\hline 5 & - & 63.15 & 7.3 \\
\hline 10 & - & 58.51 & 6.9 \\
\hline- & $\mathbf{3}$ & 78.24 & 9.3 \\
\hline- & $\mathbf{5}$ & 64.15 & 12.1 \\
\hline- & $\mathbf{8}$ & 52.78 & 14.2 \\
\hline
\end{tabular}

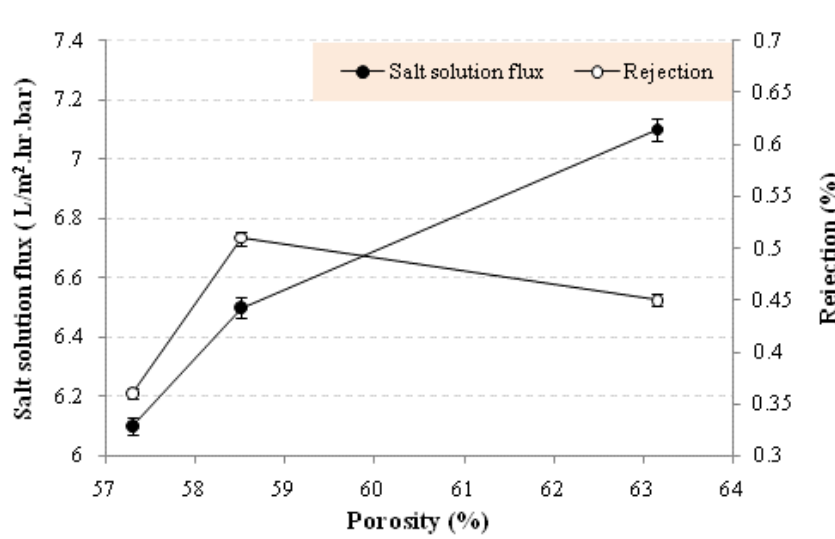

(a)

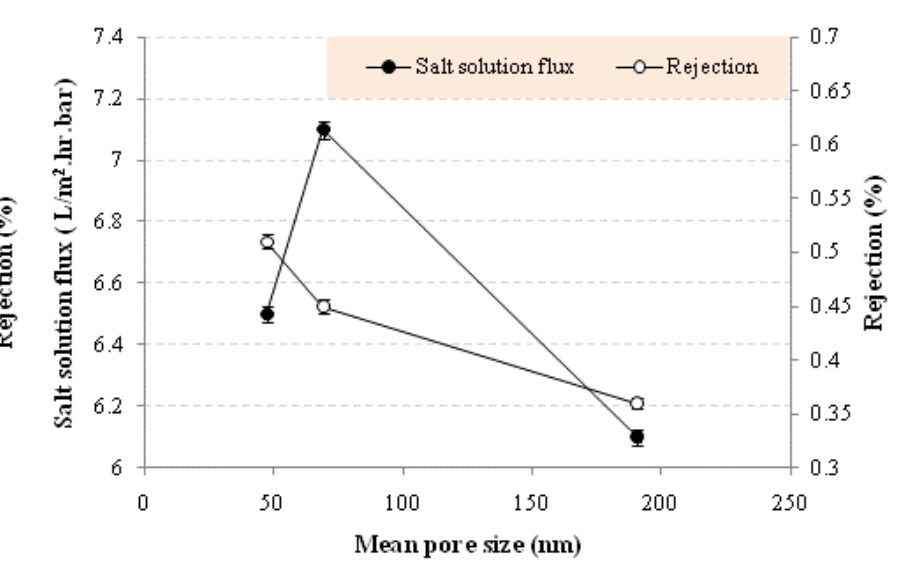

(b)

Figure 12: Effects of (a) porosity and (b) mean pore size of membranes containing PEG on salt solution flux and salt rejection.

\section{Effect of Additive Concentration on Salt Solution Flux and Salt Rejection}

The effects of porosity and mean pore size of membrane containing PEG on salt solution flux and salt rejection are shown in Figures $12 \mathbf{a}$ and $\mathbf{b}$, respectively. As seen in these figures, the salt solution flux depends to the porosity of the membrane while the salt rejection is inversely proportional to the mean pore size of the

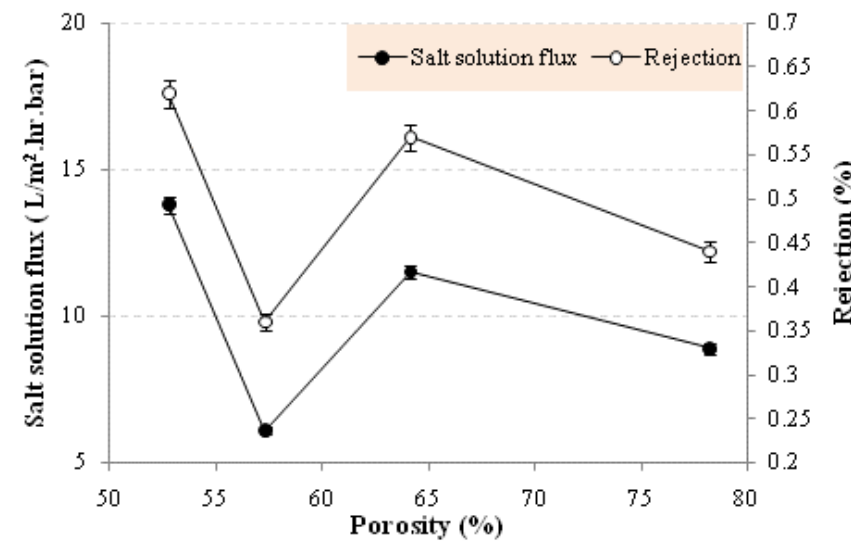

(a) membrane. However, the dependence of the salt solution flux to total porosity is not observed in the membranes containing PVP (Figure 13a). The reason is that the membranes containing PVP show different behavior as explained before for water permeation flux due to presence of PVP in the membrane matrix. On the other hand, the salt rejection in the membrane containing PVP shows again an inverse dependency to the mean pore size (Figure 13b).

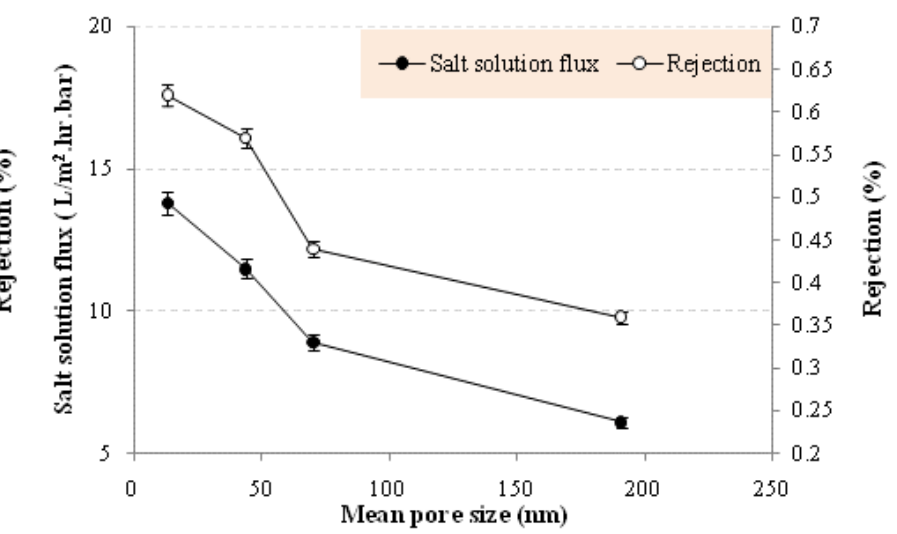

(b)

Figure 13: Effects of (a) porosity and (b) mean pore size of membranes containing PVP on salt solution flux and salt rejection. 
As the mean pore size is an index of surface porosity, the above findings may verify that the salt rejection is a function of surface porosity while depending on the applied additive, the salt permeation flux may be a function of total porosity.

\section{Effect of Additive Concentration in Support Layer on Pervaporation Performance}

Since a single-layer PES membrane has an intrinsic top layer, it might represent suitable pervaporative performance. Therefore, the performance of singlelayer membranes with 22 wt $\%$ PES and different weight percents of additive were examined. The experiments showed that these membranes are not applicable for pervaporation process because of their high permeation flux and low selectivity. Therefore, the PES membrane was coated by a selective dense PDMS top layer for pervaporative process. The details of fabrication and specification of the composite membranes were explained elsewhere [31]. Figures 14 and 15 show the effects of mean pore size (surface porosity) and total porosity of the support membrane containing PEG or PVP on pervaporative performance of the composite membranes. As seen in Figure 14, the total permeation flux of the membrane is increased as the porosity of the support layer is increased. The figure also shows that the enrichment factor is decreased by increasing the porosity. Meanwhile, Figure 15 shows that the total flux is increased by increasing mean pore size of the support layer up to a certain value and then decreased by further increasing in the pore size while an inverse trend is observed for variation of enrichment factor with the pore size. It may be concluded that that the permeation flux and enrichment factor are influenced by the total porosity of

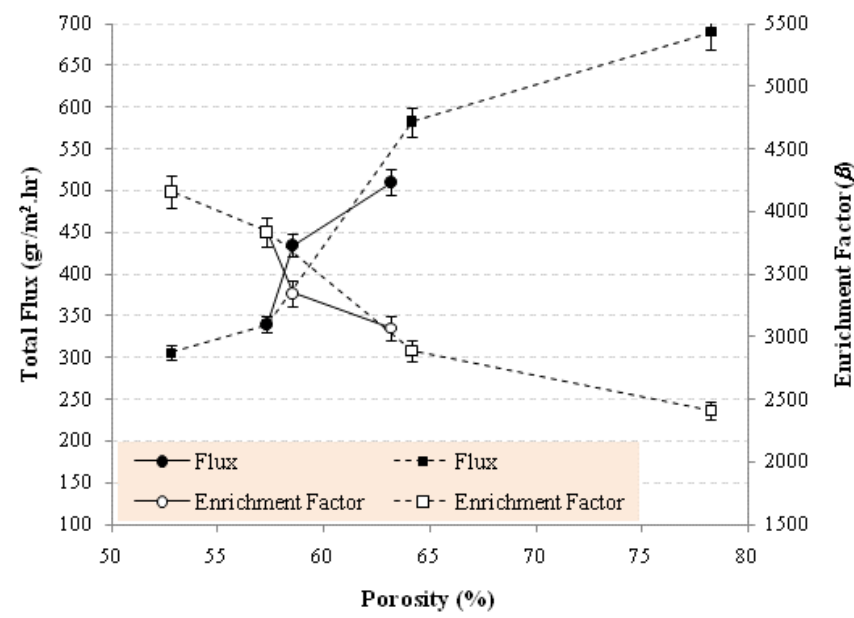

Figure 14: Effect of porosity of support layers containing PEG ( - ) or PVP (- - -) on pervaporation performance. the support layer and is hardly can be related to its mean pore size. This trend can be interpreted as the effect of porosity may be introduced directly in the total membrane resistance against mass transfer through the composite membrane while the effect of pore size of the porous support might be annulled possibly due to presence of intrinsic thin dense layer on the top of the support.

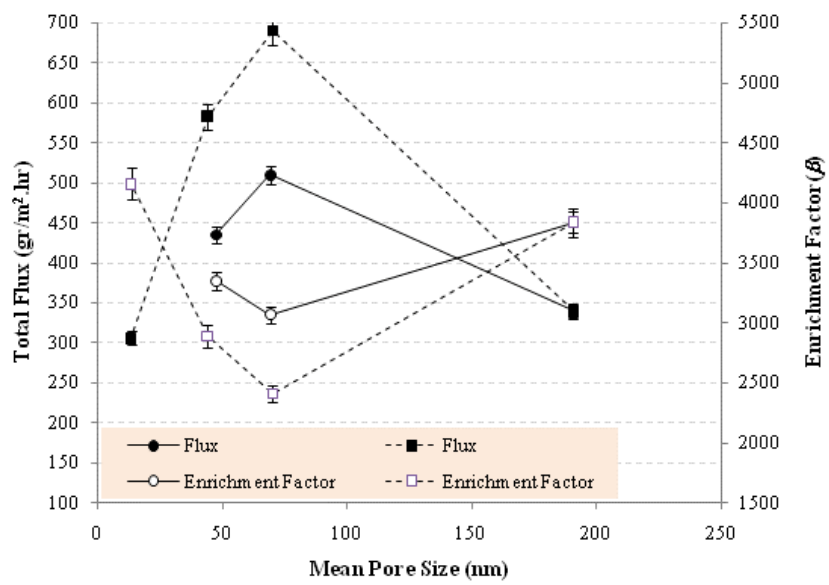

Figure 15: Effect of mean pore size of support layers containing PEG $(-)$ or PVP (---) on pervaporation performance.

\section{CONCLUSION}

In order to enhance the operational performance of nanoporous PES membrane, it was blended with different weight percents of PEG or PVP. The following results were then obtained:

1) The SEM images and porosity data show that increasing additives to a certain value is beneficial for increasing the porosity of the membrane. Also, as the coagulation bath temperature is increased, the porosity of the membrane is increased.

2) The increasing of additive concentration decreases roughness of the membrane. This effect is more pronounced in the case of PVP as the additive than that of PEG.

3) Based on the observed contact angles, the membranes made by blending PES and PVP demonstrate the highest hydrophilicity, which may be the reason of steady increase in the pure water permeation of those membranes.

4) The AFM results show that the nano-size membranes could be prepared and that the mean pore size of the membrane decreases with 
increasing additive concentration where the lower mean pore size results in more uniform distribution of the surface porosity.

5) The salt rejection is a function of surface porosity while the salt permeation flux might be a function of total porosity depending on the applied additive.

6) The permeation flux and enrichment factor are influenced by the total porosity of the support layer while there is an insignificant effect of mean pore size on these parameters.

\section{LIST OF SYMBOLS}

$$
\begin{aligned}
& \text { A } \quad=\text { Membrane surface area }\left(\mathrm{cm}^{2}\right) \\
& C_{\mathrm{A}} \quad=\text { Toluene concentration in retentate }(\mathrm{ppm}) \\
& C_{A}^{\prime} \quad=\text { Toluene concentration in permeate }(\mathrm{ppm}) \\
& C_{\mathrm{f}} \quad=\text { Salt concentration in feed }(\mathrm{ppm}) \\
& C_{\mathrm{p}} \quad=\text { Salt concentration in permeate }(\mathrm{ppm}) \\
& H \quad=\text { Membrane thickness }(\mathrm{cm}) \\
& J \quad=\text { Permeate flux }\left(\mathrm{g} / \mathrm{m}^{2} \cdot \mathrm{h}\right) \\
& L_{p} \quad=\text { Pure water permeability }\left(L / h \cdot m^{2} \cdot \text { bar }\right) \\
& m_{\mathrm{A}} \quad=\text { Mass of permeated toluene }(\mathrm{mg}) \\
& \text { M = Total mass of permeate }(\mathrm{g}) \\
& P \quad=\text { Membrane porosity (\%) } \\
& Q_{0} \quad=\text { Weight of wet membrane }(\mathrm{g}) \\
& Q_{1} \quad=\text { Weight of dried membrane }(\mathrm{g}) \\
& \text { Rejection }=\text { Salt rejection in filtration }(\%) \\
& \text { S.D = Standard deviation (-) } \\
& t \quad=\text { Experimental time interval }(\mathrm{h}) \\
& V \quad=\text { Volume of permeated water }(\mathrm{L}) \\
& V_{\mathrm{P}} \quad=\text { Total permeate volume }(\mathrm{L}) \\
& \Delta t \quad=\text { Operation time }(\mathrm{h}) \\
& \Delta P=\text { Transmembrane pressure (bar) }
\end{aligned}
$$

\section{Greek Symbols}

$$
\begin{array}{ll}
\beta & =\text { Enrichment factor }(-) \\
\rho & =\text { Liquid density }\left(\mathrm{g} / \mathrm{cm}^{3}\right)
\end{array}
$$

\section{REFERENCES}

[1] She M, Hwang ST. Effects of concentration, temperature, and coupling on pervaporation of dilute flavor organics. J Membr Sci 2006; 271: 16-28.

https://doi.org/10.1016/j.memsci.2005.07.005

[2] Hasanoglu A, Salt $Y$, Keleser S, Ozkan S, Dincer S. Pervaporation separation of organics from multicomponent aqueous mixtures. J Chem Eng Process 2007; 46: 300-306. https://doi.org/10.1016/j.cep.2006.06.010

[3] Schnabel S, Moulin P, Nguyen QT, Roizard D, Aptel P. Removal of volatile organic components (VOCs) from water by pervaporation: separation improvement by Dean vortices. J Membr Sci 1998; 142: 129-141. https://doi.org/10.1016/S0376-7388(97)00326-8

[4] Peters TA, Poeth CHS, Benes NE, Buijs HCWM, Vercauteren FF, Keurentjes JTF. Ceramic-supported thin PVA pervaporation membranes combining high flux and high selectivity; contradicting the flux-selectivity paradigm. J Membr Sci 2006; 276: 42-50. https://doi.org/10.1016/j.memsci.2005.06.066

[5] Kreiter R, Wolfs DP, Engelen CWR, van Veen HM, Vente JF. High-temperature pervaporation performance of ceramicsupported polyimide membranes in the dehydration of alcohols. J Membr Sci 2008; 319: 126-132. https://doi.org/10.1016/j.memsci.2008.03.026

[6] Hasanoglu A, Salt Y, Keleser S, Dincer S. The esterification of acetic acid with ethanol in a pervaporation membrane reactor. Desalination 2009; 245: 662-669. https://doi.org/10.1016/j.desal.2009.02.034

[7] Ray S, Ray SK. Separation of organic mixtures by pervaporation using crosslinked and filled rubber membranes. J Membr Sci 2006; 285: 108-119. https://doi.org/10.1016/j.memsci.2006.08.009

[8] Rautenbach R, Albrecht R. Membrane processes. New York: John Wiley; 1989.

[9] Norman NN, Anthony G, Winston Ho WS, Matsuura T. Advanced membrane technology and applications. New Jersey: John Wiley; 2008.

[10] Feng X, Huang RYM. Preparation and performance of asymmetric polyetherimide membranes for isopropanol dehydration by pervaporation. J Membr Sci 1996; 109: 165172. https://doi.org/10.1016/0376-7388(95)00198-0

[11] Hof JA, Reuvers AJ, Boom RM, Rolevink HHM, Smolders CA. Preparation of asymmetric gas separation membranes with high selectivity by a dual-bath coagulation method. J Membr Sci 1992; 70: 17-30. https://doi.org/10.1016/0376-7388(92)80076-V

[12] Chakrabarty B, Ghoshal AK, Purkait MK. Preparation, characterization and performance studies of polysulfone membranes using PVP as an additive. J Membr Sci 2008; 315: 36-47.

https://doi.org/10.1016/j.memsci.2008.02.027

[13] Jadav GL, Aswal VK, Singh PS. In-situ preparation of polydimethylsiloxane membrane with long hydrophobic alkyl chain for application in separation of dissolved volatile organics from wastewater. J Membr Sci 2015; 492: 95-106. https://doi.org/10.1016/j.memsci.2015.05.050

[14] Greer DR, Ozcam AE, Balsara NP. Pervaporation of organic compounds from aqueous mixtures using polydimethylsiloxane-containing block copolymer membranes. AIChE J 2015; 61: 2789-2794. https://doi.org/10.1002/aic.14876

[15] Jung B, Yoon Jo K, Kim B, Rhee HW. Effect of molecular weight of polymeric additives on formation, permeation properties and hypochlorite treatment of asymmetric polyacrylonitrile membranes. J Membr Sci 2004; 243: 45-57. https://doi.org/10.1016/j.memsci.2004.06.011 
[16] Rahimpour A, Madaeni SS. Polyethersulfone (PES)/cellulose acetate phthalate (CAP) blend ultrafiltration membranes: Preparation, morphology, performance and antifouling properties. J Membr Sci 2007; 305: 299-312. https://doi.org/10.1016/j.memsci.2007.08.030

[17] Jin TT, Zhao ZP, Chen KC. Preparation of a poly(vinyl chloride) ultrafiltration membrane through the combination of thermally induced phase separation and non-solvent-induced phase separation. J Appl Polym Sci 2016; 42953: 1-12. https://doi.org/10.1002/app.42953

[18] de Bruijn FT, Suna L, Oluji Z, Jansens PJ, Kapteijn F. Influence of the support layer on the flux limitation in pervaporation. J Membr Sci 2003; 223: 141-156. https://doi.org/10.1016/S0376-7388(03)00318-1

[19] Tan S, Li L, Zhang Z, Wang Z. The influence of support layer structure on mass transfer in pervaporation of composite PDMS-PSF membranes. J Chem Eng 2010; 157: 304-310. https://doi.org/10.1016/j.cej.2009.10.060

[20] Bode E, Hoempler C. Transport resistances during Pervaporation through a composite membrane: experiments and model calculations. J Membr Sci 1996; 113: 43-56. https://doi.org/10.1016/0376-7388(95)00213-8

[21] Kim HJ, Nah SS, Ryul B. A new technique for preparation of PDMS pervaporation membrane for VOC removal. Adv Environ Res 2002; 6: 255-264. https://doi.org/10.1016/S1093-0191(01)00056-9

[22] Rezakazemi M, Shahidi K, Mohammadi T. Synthetic PDMS composite membranes for pervaporation dehydration of ethanol. Desalin Water Treat 2015; 54: 1542-1549.

[23] Trifunovic O, Tragardh G. The influence of support layer on mass transfer of homologous series of alcohols and esters through composite pervaporation membranes. J Membr Sci 2005; 259: 122-134.

https://doi.org/10.1016/j.memsci.2005.03.011

[24] Rautenbach R, Helmus FP. Some considerations on mass transfer resistances in solution-diffusion type membrane processes. J Membr Sci 1994; 87: 171-181. https://doi.org/10.1016/0376-7388(93)E0130-C

[25] Sun D, Yang Q-C, Sun H-L, Liu J-M, Xing Z-L, Li B-B. Effects of PES support layer structure on pervaporation performances of PDMS/PES hollow fiber composite membranes. Desalin Water Treat 2016; 57: 9123-9135. https://doi.org/10.1080/19443994.2015.1028458

[26] Zhu JM, Li G, Jiang LY. Fabrication and structural tuning of novel composite hollow fiber membranes for pervaporation. $J$ Appl Polym Sci 2016; 43324: 1-13. https://doi.org/10.1002/app.43324

[27] Idris A, Yet LK. The effect of different molecular weight PEG additives on cellulose acetate asymmetric dialysis membrane performance. J Membr Sci 2006; 280: 920-927.

https://doi.org/10.1016/j.memsci.2006.03.010

[28] Han MJ, Nam SI. Thermodynamic and rheological variation in poly(sulfone) solution be PVP and its effect in the preparation of phase inversion membrane. J Membr Sci 2002; 202: 55-61.

https://doi.org/10.1016/S0376-7388(01)00718-9

[29] Li JF, Xu ZL, Yang H, Yu LY, Liu M. Effect of $\mathrm{TiO}_{2}$ nanoparticles on the surface morphology and performance of microporous PES membrane. Appl Surf Sci 2009; 255: 47254732.

https://doi.org/10.1016/j.apsusc.2008.07.139
[30] Madaeni SS, Rahimpour A, Barzin J. Preparation of polysulphone ultrafiltration membranes for milk concentration: effect of additives on morphology and performance. Iran Polym J 2005; 14: 421-428.

[31] Salehi S, Mortaheb HR, Barzin J, Ehsani MR. Pervaporative performance of a PDMS/blended PES composite membrane for removal of toluene from water. Desalination 2012; 287 : 281-289. https://doi.org/10.1016/j.desal.2011.08.062

[32] Barth C, Goncalves MC, Pires ATN, Roeder J, Wolf BA. Asymmetric polysulfone and polyethersulfone membranes: effects of thermodynamic conditions during formation on their performance. J Membr Sci 2000; 169: 287-299. https://doi.org/10.1016/S0376-7388(99)00344-0

[33] Barzin J, Sadatnia B. Correlation between macrovoid formation and the ternary phase diagram for polyethersulfone membranes prepared from two nearly similar solvents. J Membr Sci 2008; 325: 92-97.

https://doi.org/10.1016/j.memsci.2008.07.003

[34] Barzin J, Feng C, Khulbe KC, Matsuura T, Madaeni SS, Mirzadeh $\mathrm{H}$. Characterizatin of polyethersulfon hemodialysis membrane by ultrafilteration and atomic force microscopy. J Membr Sci 2004; 237: 77-85.

https://doi.org/10.1016/j.memsci.2004.02.029

[35] Barzin J, Sadatnia B. Theoretical phase diagram calculation and membrane morphology evaluation for water/solvent/ polyethersulfone systems. Polymer 2007; 48: 1620-1631. https://doi.org/10.1016/j.polymer.2007.01.049

[36] Dal-Cin M, Tam CM, Guiver M, Tweddle TA. Polysulfone membranes. V. poly(phenylsulfone)(Radel R)- poly(vinyl pyrrolidone) membranes. J Appl Polym Sci 1994; 54: 783792.

https://doi.org/10.1002/app.1994.070540609

[37] Barzin J, Madaeni SS, Mirzadeh H. Effect of preparation conditions on morphology and performance of hemodialysis membranes prepared from polyether sulphone and polyvinyl pyrrolidone. Iran Polym J 2005; 14: 353-360.

[38] Madaeni SS, Barzin J, Jokar Z. Evaluation of the morphology and performance of polyether sulfone reverse osmosis composite and non-composite membranes. Polym Polym Compos 2009; 17: 101-108.

[39] Liu Y, Koops GH, Strathmann H. Characterization of morphology controlled polyethersulfone hollow fiber membranes by the addition of polyethylene glycol to the dope and bore liquid solution. J Membr Sci 2003; 223: 187-199. https://doi.org/10.1016/S0376-7388(03)00322-3

[40] Kim JH, Lee KH. Effect of PEG additive of membrane formation by phase inversion. J Membr Sci 1998; 138: 153163.

https://doi.org/10.1016/S0376-7388(97)00224-X

[41] Chuang WY, Young TH, Chiu WY, Lin CY. The effect of polymeric additives on the structure and permeability of poly(vinylalcohol) asymmetric membranes. Polymer 2000; 41: 5633-5641.

https://doi.org/10.1016/S0032-3861(99)00818-6

[42] Hobǽk TC, Leinan KG, Leinaas HP, Thaulow C. Surface nanoengineering inspired by evolution. BioNanoSci 2011; 1 : 63-77.

https://doi.org/10.1007/s12668-011-0014-5 